\title{
Artigos
}

Vera Lucia Chacon Valença'

Lidiani Morgenroth Fontana²

\section{As crianças e as aprendizagens pelo cotidiano: jogos, comunicações e relações afetivas}

\begin{abstract}
Resumo: Este artigo apresenta os resultados de uma pesquisa de viés etnográfico realizada com 24 crianças, de 3 e 4 anos, de um Centro de Educação Infantil de uma cidade do sul de Santa Catarina que teve por objetivo descrever e refletir sobre suas comunicações, jogos e relações afetivas, nas interações ocorridas entre pares. De inspiração sociointeracionista, o trabalho recebeu as contribuições dos pesquisadores da Sociologia da Infância, da Psicologia, da Antropologia e da Filosofia, tendo por figura de fundo as aprendizagens pelo cotidiano, na perspectiva apresentada por Gilles de Brougère e por Bárbara Rogoff. Observaram-se comportamentos provenientes de uma seletividade empática; reproduções interpretativas no desempenho de papéis dos jogos simbólicos e particularidades de comportamentos relacionadas a contextos diversos.
\end{abstract}

Palavras-chave: Aprendizagens pelo cotidiano. Interações. Comunicações.

\section{Children and everyday learning: games, communication and affective relationships}

Abstract: The theft of playful practices and disciplining through the body in many institutions of early childhood education are more than sporadic actions - they become something that is within normalcy. The main objectives of this article are: to promote a discussion and reflection on the disciplinarization of childhood through the control of children, either by spatial distribution, by teachers' behavior or by the persistence of historical paradigms that insist that the presence of play against learning and child development. Also, it seeks to alert and defend the importance of the playful in the training of children, refuting pressures, mainly external to the institutions of Early Childhood Education, which secondarily. It is based on the conception of children as subjects of rights - among them, the one of playing, secured by many legal documents that aim at the protection of the childhood. However, it should be noted that many institutions of early childhood education, which are under pressure from the neoliberal logic of national and international policies, are more concerned with the preparation of work than with the rights of children. In this sense, it is necessary that all who act directly with the children do not give up access to the play activity, since it is a child's right that needs to be guaranteed in the context of Early Childhood Education.

Keywords: Learning by the quotidian. Interactions. Communication.

'Doutorado em Phsychologie Appliquée - Sorbone - Paris V. Pós-Doutorado no Instituto Del Consiglio Nazionale delle Ricerche di Roma. Professora tempo integral do Programa de Pós-Graduação da Universidade do Sul de Santa Catarina. Email: veravalenca@uol.com.br

2Pedagoga (Unisul), responsável pela brinquedoteca da Unisul no período de 2013 a 2016. Professora da rede Municipal de Ensino de Treze de Maio. E-mail: lidyfontana@hotmail.com 
ste artigo tem por propósito apresentar os resultados de uma pesquisa de inspiração etnográfica realizada com 24 crianças, de 3 e 4 anos, de um Centro de Educação Infantil (CEI) localizado em uma cidade do sul de Santa Catarina. Ela teve por objetivo descrever e refletir sobre as comunicações, jogos e relações afetivas entre pares, visando à compreensão das interações numa perspectiva das aprendizagens pelo cotidiano. As observações, realizadas por uma das pesquisadoras, ocorreram num período de dois meses e tiveram por suporte teórico uma abordagem sociointeracionista. Como figura de fundo, encontram-se as noções sobre as aprendizagens pelo cotidiano, na perspectiva apresentada por Brougère (2012a) e a respeito do pressuposto de que é participando que se aprende, com base nas ideias do mesmo autor e naquelas de Bárbara Rogoff, por ele entrevistada, com transcrição na mesma obra.

Sabe-se que a imersão na vida cotidiana realça as múltiplas aprendizagens dela resultantes que são propulsoras do desenvolvimento e contribuem para a conquista do mundo pela criança.

A pesquisa assimilou o que propõe Corsaro (2011), no que diz respeito à "reprodução interpretativa", expressão criada por ele para afirmar que as crianças participam ativamente da sociedade inovando e criando a partir das informações que recebem dos adultos. Elas não se limitariam somente a internalizar, mas interpretam e produzem a "cultura de pares", na qual a linguagem e as rotinas são ferramentas fundamentais. Corsaro (2011) criou um modelo gráfico para representar a reprodução interpretativa: o da Rede Global. Esta é constituída por estruturas institucionais da cultura adulta que vão envolvendo as crianças nas suas tramas/redes, ao mesmo tempo em que elas vão construindo suas próprias redes de relações sociais. As crianças, portanto, refletem seus pertencimentos evolutivos que partem da família e vão se expandindo para outros campos sociais, como: educativos, ocupacionais, comunitários, econômicos, religiosos, culturais cada vez mais amplos. A Rede Global, por conseguinte, valoriza os espaços institucionais para estudar as reproduções interpretativas e as interações que se dão em vários desses espaços.

Sirota (2012), concordando com o que propõe Corsaro (2011), pronuncia-se afirmando que no processo de "aculturação" as crianças utilizam os jogos de papéis, particularmente significativos à compreensão da sua construção coletiva. A autora explica que é através das representações de papéis que as crianças criam "predisposições para sua vida futura e assim contribuem para a reprodução e mudança do mundo adulto" (CORSARO apud SIROTA, 2012, p. 284).

Os psicólogos Vigotski (1998) e Wallon (1989) valorizam sobremaneira as interações sociais para compreender o desenvolvimento humano. Eles consideram que o bebê é um ser biologicamente 
sociocultural que expressa, desde a mais tenra idade, suas emoções, preferências e percepções. Se os psicólogos forem cognitivistas, seus interesses recaem sobre a construção cognitiva das emoções.

São recentes os estudos sobre as interações entre crianças realizados pelos sociólogos. Delalande (2012, p.67) esclarece: “As interações entre crianças são objeto de poucos trabalhos, já que é a da relação da educação com o adulto que interessa mais aos sociólogos, etnólogos e pedagogos, visto que é a criança como ser em desenvolvimento que constitui o objeto de atenção dos psicólogos". Mas, como lembra Sirota (2006), observa-se que o tema a respeito de uma aprendizagem social entre crianças passou a ser abordado só nas últimas décadas pelos sociólogos. Isso se deveria em parte, de acordo com Delalande (2012), à herança que os franceses receberam de Émile Durkheim, para quem as crianças não estariam ainda maduras o suficiente para participar da vida social. Porém, e ainda conforme Delalande (2012, p. 68), houve sim uma referência a respeito da capacidade das crianças de se formarem mutuamente, quanto de viver o presente, desde que permitido pelos adultos, ideia explorada em 1950 por Roger Cousinet, discípulo de Durkheim, na obra La vie social des enfants.

Nesse sentido, é importante estudar as crianças em espaços e tempos mais livres da tutela dos adultos. Por isso Delalande (2012), entre outros, investiga-as nos pátios de recreio, onde "qualquer troca pode levar a uma aprendizagem, quer horizontal entre crianças, quer vertical, de adulto para crianças" (DELALANDE, 2012, p. 66). Para Delalande (2003), a cultura infantil "é o conjunto de práticas, de conhecimentos, de competências e de comportamentos que uma criança deve conhecer e dominar para integrar o grupo de pares" (DELALANDE, 2003, p. 3). Corresponde àquilo que as crianças constroem a partir do que lhes é disponibilizado pelos adultos. Elas elaboram regras, e atribuem uma dimensão simbólica aos jogos. Então, fazer com os outros, submeter-se a um código para serem aceitas pelos pares, supõe o domínio de saberes e de fazeres, isto é, para pertencer a um grupo elas necessitam de certas experiências e competências. Elas dominam um saber no presente e compreendem o que isso significa diante dos adultos e dos pares. Existiria, portanto, um patrimônio infantil, lúdico, uma cultura infantil, que possibilitaria às crianças aproximarem-se entre si, brincar, jogar, e que está associado à maturidade física e intelectual comum, que se transmite entre elas (DELALANDE, 2003).

Brougère (2012b) refere-se aos conhecimentos do cotidiano que "remetem ao mais banal, às rotinas, às repetições da vida" (BROUGÈRE, 2012b, p. 11). As rotinas não se restringem, apenas, ao uso da memória. É o que afirmam Delalande (2003, 2012) e Corsaro (2011), e o que demonstrou Florestan Fernandes (2004) na pesquisa Astrocinhas do Bom Retiro: os jovens não só preservam, mas inovam aquilo que os adultos lhes transmitiram. Portanto, no cotidiano desenvolvem-se aprendizagens que são "um conjunto de recursos que nos permite economizar, apoiar-nos no que já fizemos, mas também no que outros fizeram, pois as rotinas podem ser transmitidas" (BROUGÈRE, 2012b, p. 13). O cotidiano é, pois, mutante e as pessoas, dinâmicas.

O termo participação implica em admitir uma relação de reciprocidade, logo, "a aprendizagem é uma maneira de fažer com" (BROUGÈRE, 2012a, p. 318). Assim, o processo de participação favorece a aprendizagem. É participando que as crianças aprendem na escola, na família e nos demais espaços sociais, 
incluindo a cidade: as ruas, o pátio de recreio, os centros culturais, etc. Ao educador caberia, entre outros, focar seu trabalho na organização das atividades. Torna-se, então, imperativo oferecer às crianças possibilidades de observar, escutar, falar, expressar-se de várias maneiras; participar, de ficar mais livres em algumas ocasiões para utilizarem, do seu "jeito", o tempo e o espaço, e construírem sua própria cultura, além de reproduzirem interpretativamente aquela do adulto.

As observações têm demonstrado que as crianças participam das práticas sociais/culturais, onde não só aprendem, mas também ensinam os adultos, inclusive sobre quem são e do que são capazes.

\section{A pesquisa de campo: caminhos metodológicos, registro das observações e análise dos dados coletados}

Tendo por objetivo descrever e refletir sobre as comunicações, jogos e relações afetivas nas interações ocorridas entre pares de crianças de 3-4 anos, foi realizada uma pesquisa de viés etnográfico pelo fato de ser um método, segundo Corsaro (2011, p. 63), "eficaz para estudar crianças porque muitos recursos de suas interações e culturas são produzidos e compartilhados no presente e não podem ser obtidos facilmente por meio de entrevistas reflexivas ou questionário". Tal método possibilita a descrição e o registro detalhado sobre como as crianças vivem sua infância. Como instrumento de coleta de dados foram utilizadas observações as quais permitem que os pesquisadores "se coloquem em posição neutra para documentar as culturas de pares infantis" (CORSARO, 2011, p. 65). A pesquisa foi realizada em setembro, outubro e novembro de 2015, com 24 crianças de 3-4 anos, de um CEI de Santa Catarina.

Corsaro (2011) lembra que para ter sucesso nas observações intensivas e prolongadas existem pré-requisitos, entre os quais a aceitação do pesquisador pelas crianças, o que possibilitaria seu engajamento/participação no processo investigativo, fato que criou uma grande expectativa nas pesquisadoras.

Para registrar as observações foi utilizado um Diário de Campo. ${ }^{3}$ Algumas brincadeiras no pátio foram fotografadas, tendo havido o cuidado de "esconder" o rosto das crianças, para evitar expô-las desnecessariamente; os vídeos foram evitados pelo mesmo motivo.

A leitura dos registros possibilitou a criação de algumas categorias de análise, como: interações: eu e o outro; contextos culturais; construção de grupos: inserção/exclusão; brincadeiras e jogos de papéis sociais; questões de gênero e curiosidade sexual; interações pesquisadora-crianças. Neste artigo não constam todos os registros pelo limite de espaço. Os registros transcritos do Diário de Campo são apresentados neste texto, em cenas enumeradas.

A primeira aproximação com as crianças ocorreu no mesmo momento em que a professora foi contatada. Enquanto se desenvolvia a conversa a respeito do processo da pesquisa (objetivo, forma, dias, momentos, tempos e espaços de observações), já chamava atenção uma conversa entre duas crianças, conforme detalhado abaixo no Diário de Campo.

\footnotetext{
${ }^{3}$ Embora as observações tenham sido feitas por uma das pesquisadoras, tendo por propósito preservar a coerência textual, o texto
} será todo escrito na terceira pessoa do singular. 
Cena 1: Duas crianças de 3-4 anos encontravam-se na salinha do CEI. Uma menina varria o chão da salinha, no qual havia papéis picados. Enquanto se dedicava ao trabalho, um menino aproximou-se arrastando-se e espelhando todo o monte de papel que a menina havia formado. Nervosa ela gritou:

- 'Ei, sai daqui que eu estou varrendo.'

- 'E eu estou nadando' - respondeu ele rapidamente.

- 'Mas você pode nadar em outro lugar, olha quanto espaço' (gesticulando com as mãos mostrando o grande espaço que ele possuía).

- 'E você pode varrer em outro lugar, olha quanto espaço' (repetiu o gesto da menina). (Diário de Campo, 01/09/2015).

Sobre a cena 1, Corsaro (2011, p. 161) afirma que a proteção do espaço interativo é a tendência das crianças em idade pré-escolar, tendência essa que está "diretamente relacionada à fragilidade da interação de pares, às várias possibilidades de interrupção na maioria dos ambientes pré-escolares e no desejo infantil de preservar o controle sobre atividades compartilhadas". Na cena mencionada, a disputa pelo espaço causou um desentendimento expresso oralmente. Tal mal-estar nem sempre é solucionado verbalmente. Há ocasiões em que as crianças partem para agressões físicas, empurra-empurra, puxa-puxa o brinquedo de interesse mútuo. O menino reage, pois está "nadando", realizando uma brincadeira imaginativa, na qual ele "subordina o objeto, o local da brincadeira, o próprio corpo, etc. aos propósitos da imaginação [...]” (CARVALHO; PEDROSA; ROSSETTI-FERREIRA, 2012, p. 192-193).

As observações sobre as aprendizagens pelo cotidiano lembram que "o saber não existe em si pronto para ser transmitido, mas encontra-se inextricavelmente ligado à atividade dos sujeitos em contextos diversos, comuns e incomuns, sempre particulares e situados" (BROUGÈRE; ULMANN, 2012, p. 03).

Montandon e Longchamp (2007, p. 121) lembram, a respeito das brincadeiras, que as crianças "definem e constroem suas próprias experiências". E estas aparecem de modo muito espontâneo no brincar, quando ocorrem trocas de experiências que são fundamentais para o desenvolvimento, e aprendizagens de regras do bem viver. A invasão do espaço pelo menino, participante da cena supramencionada, explicita sua vontade, em última instância, de "entrar na brincadeira dela", mesmo partindo de uma "transgressão", que se constituiu, no caso, na invasão do território da colega. O brincar é compreendido como um espaço fundamental para a aprendizagem entre pares, o que leva à consolidação da cultura. Como o expressa Borba (2007, p. 12).

[...] a brincadeira é um fenômeno da cultura, uma vez que se configura como um conjunto de práticas, conhecimentos e artefatos construídos e acumulados pelos sujeitos nos contextos históricos e sociais em que se inserem. Representa, dessa forma, um acervo comum sobre o qual os sujeitos desenvolvem atividades conjuntas. Por outro lado, o brincar é um dos pilares da constituição de culturas da infância, compreendidas como significações e formas de ação social específicas que estruturam as relações das crianças entre si, bem como os modos pelos quais interpretam, representam e agem sobre o mundo.

Aos poucos, as crianças iam encontrando motivo para se aproximarem, ou chamar atenção com algum gesto ou palavra, como no exemplo a seguir: "Tia, hoje tá [sic bem frio, né [sic], tem que colocar bastante camisa" (fala de Ana, Diário de Campo 09/09/2015). Mas nem sempre o sucesso na aproximação era garantido. Por alguns momentos, a sensação era de total rejeição delas, como mostram as seguintes cenas: "Cena 2: Aproximação de uma menina que organizava os sapatinhos de bonecas de 
acordo com seus pares. À medida que a distância ia diminuindo, ela vai recuando, até que olha com braveza. Pega os sapatinhos e sai correndo.” (Diário de Campo, 11/09/2015).

Outra cena evidencia o papel de líder assumido por uma das crianças que assim se expressa: "Ninguém faz nada sem eu [sid]". E, submissa, a coleguinha lembra o que precisa ser feito, sem, contudo, ousar tomar o lugar da outra, que demonstra ter competência para a realização da tarefa, assumindo o protagonismo da cena. Assistiu-se, então, a mais uma explicitação do saber-fazer como afirmação do poder de uma das crianças. E são exemplos das práticas lúdicas que fazem parte da cultura infantil.

Cena 3: Duas meninas brincam de boneca e uma delas sente frio. O diálogo foi:

- 'Ana, a gente precisa colocar blusas nas nossas filhas', disse Maria, enquanto com dificuldades tentava colocar sua própria blusa.

- 'Mas será o Benedito, ninguém faz nada sem eu [sic] nessa casa!', exaltou Ana, pondo as mãos na cintura (Diário de Campo, 11/09/2015).

$\mathrm{Na}$ turma, nenhuma criança sabe amarrar cadarço, mas, durante as observações, uma conversa chamou atenção. Bruno não conseguia amarrar o cadarço do tênis, e é auxiliado por um colega que tem certa competência para solucionar o problema, com um "jeitinho": Cena 4: Uma criança tenta em vão amarrar o cadarço do seu sapato. Tiago então lhe diz: 'Oh, coloca assim por dentro que ele não cai e não precisa chamar a tia' (Diário de Campo, 16/09/2015).

As aprendizagens entre pares estimulam a independência. Assim, vão ocorrendo trocas de saberes, e as crianças vão inventando soluções que compartilham com os companheiros. Fica também evidenciada a empatia de Tiago pelo coleguinha, a quem ele tenta ajudar. E a gentileza de Tiago para com Bruno é uma das características largamente reconhecidas entre pares, conforme constatou Delalande (2003).

As cenas observadas levaram a reflexões sobre as aprendizagens que ocorrem entre crianças, a respeito das quais Corsaro (1992 apud MULLER; CARVALHO, 2009, p. 131) diz que "quando as crianças reconhecem que têm capacidade de produzir seu próprio mundo partilhado sem depender diretamente dos adultos, transforma-se a própria natureza do processo de socialização", que irá ter por suporte as trocas sociais entre pares, ou seja, a socialização horizontal.

Para brincarem juntas, algumas condições precisam ser respeitadas: isso leva a rejeições e aceitações no grupo. O coração também fala alto nessas ocasiões: a empatia, como na cena 4, anterior, evidencia-se às vezes, na inclusão ou exclusão de pares nos grupos. Veja-se a cena a seguir.

Cena 5: Aproximo-me de um grupo onde as crianças estão brincando, quando surge uma pequena confusão entre elas.

Pesquisadora: 'Oi, do que você está brincando?'

Ana responde: 'Eu estou brincando com a Gi, mas a Maria não perde essa mania de pegar as coisas que eu quero pegar.' (furiosa).

Gi: 'Tu também não é santa, Ana!'

Pesquisadora: 'E do que você e a Gi estão brincando?'

Ana: 'Tô [sic] pensando em brincar de médica.'

Pesquisadora: 'Como se brinca de médica?'

Ana: 'Assim, a gente vira a bunda [sic] de alguém e dá a injeção.'

Pesquisadora: 'E não dói?’

Ana: 'Essa não, é só um pau. Mas a que a gente ganha no posto dói, eu sempre choro.'

Pesquisadora: 'Por quê?'

Ana: 'Se eu colocar esse pau na sua carne não vai doer? Então [...] mesma coisa.'

Pesquisadora: 'Verdade.' (E fico sem saber o que dizer). (Diário de Campo, 09/09/2015). 
As crianças colocam regras entre elas e as defendem com muita energia: as líderes submetem as outras crianças à "sua autoridade", e elas são obedecidas como sendo regras do grupo, são regras que foram apropriadas por elas e que as auxiliam ao saber-viver entre si.

Esta cena, descrita acima, lembra o que Korczak afirmou em seu livro Quando eu voltar a ser criança: "O mais importante da brincadeira é com quem a gente está brincando. [...] A brincadeira precisa ser bem construída, o que nem sempre se consegue; então, quando a gente consegue, quer aproveitar" (KORCZAK, 1981, p. 47).

Conviver com o outro não é fácil, e, diariamente, ocorrem diversos sentimentos que permeiam as relações entre adultos, entre eles e as crianças ou entre as crianças e seus pares. A esse respeito, Carvalho, Pedrosa e Rossetti-Ferreira (2012, p. 187) ressaltam que:

[...] qualquer observador atento pode reconhecer que crianças se interessam por outras crianças desde muito pequenas e têm muita disponibilidade para a troca social com esses parceiros mais parecidos com elas do que os adultos. É claro que essa troca nem sempre é fácil: há problemas de comunicação e de convivência com outras vontades, em geral mais sérios do que os que ocorrem entre crianças e adultos com quem se relacionam.

A tendência para o compartilhamento de saberes, evidenciada, inclusive, na cena recémmencionada, mostra um pouco da disponibilidade das crianças nas comunicações. Estas ocorrem não só através das palavras, mas gestos, expressões gráficas, etc. Em várias ocasiões, "convicções" e "certezas" se "chocam", mas também ocorrem "encontros" entre aprendizagens durante as interações. O escutar o outro da mesma idade vai possibilitando um enriquecimento no repertório dos saberes infantis que serve de base à criação e à recriação do seu universo, subsidiando a cultura de pares. Nas rotinas das meninas, elas assumem diversos papéis, entre os quais o de mães, de mulheres preocupadas com o "culto à beleza".

Cena 6: Um grupo de meninas reúne-se perto das mochilas. Elas passam batons e perfume. Eu me aproximo e, mesmo sem perguntar, ouço a justificativa:

- 'É preciso ficar bonita para o café da manhã.'

Todas soltam risadas encantadoras (Diário de Campo, 16-09-2015).

Esse jogo coletivo impõe uma submissão às regras comuns. Isto é, "as crianças vivem essas regras como fazendo parte do seu patrimônio lúdico, que consiste em uma apropriação das regras do saber-viver (DELALANDE, 2003, p. 10).

É importante apontar que os saberes do cotidiano, segundo Pierre Dasen (apud NGENG), "devem ser definidos em sua relação à educação informal por oposição à educação formal, que se desenrola na escola" (2012, p. 293). Tais saberes são conhecimentos adquiridos por aprendizagens e experiências que englobam "as atividades que se passam em torno do(s) e no(s) lugar(es) natural(ais) de vida do indivíduo e das quais ele participa” (DASEN apud NGENG, 2012, p. 293). Eles põem em evidência "as especificidades do meio em que a criança vive, assim como a adaptação contínua desse meio às suas necessidades" (DASEN apud NGENG, 2012, p. 294). No diálogo da cena a seguir percebe-se um compartilhamento de aprendizagem entre uma criança residente na zona rural, Nicolas, e João, morador da cidade, evidenciando um viés intercultural entre pares.

Cena 7: A professora entrega uma bolinha de massinha pequena para cada uma das crianças que se juntam numa grande mesa. Escuto: 
- 'A minha tá [sic] dura.' (João)

- 'É só cuspir nela.' (Nicolas)

- 'Ui, que nojo!' (João)

- 'Não é nojo, baba de café não é nojo, nojo é baba de vaca.' (Nicolas). (Diário de Campo, 30-09-2015).

As interações revelam relações empáticas, “amizades”, mesmo que talvez não sejam duradouras, que determinam a inclusão de alguns colegas nas brincadeiras. As crianças cuidam umas das outras: elas protegem, auxiliam colegas e demonstram afeto. Foi presenciada a seguinte cena:

Cena 8: Durante o café uma conversa curiosa é presenciada.

- 'Se você não comer, a tia não vai deixar você ir no [sic] parque.'

- 'Mas a tia nem tá [sic] vendo.'

- 'Tá [sic] sim, ela tá [sic] só de olho.' (Diário de Campo, 02-10-2015).

Os espaços de aprendizagens são os mais diversos. Brougère (2012a) enfatiza, no seu livro Aprendizagem pelo cotidiano, a posição segundo a qual "participar é aprender". Ele entrevista Rogoff, que, por sua vez, afirma:

Trata-se de participar, de querer participar, de integrar um novo participante, de assumir essa ou aquela atividade. Assim, se aprende, sem necessariamente se dar conta disso, sem nem sempre querer. O que importa é participar, fazer com os outros, ser membro de uma comunidade de prática. A aprendizagem não é separada, isolada, é o efeito da participação, 'avaliada' pela minha transformação em minha capacidade de participar, o que alguns podem chamar de desenvolvimento (BROUGÈRE, 2012a, p. 313-314).

O conceito de aprendizagem utilizado por Brougère (2012a) salienta, como já dito, a participação nas tarefas cotidianas. Ele aponta:

A aprendizagem é definida, tanto por Rogoff quanto por Lave ou Waenger, como um processo de transformação de participação nas atividades ou práticas culturais em curso. Aprender com a vida cotidiana seria então participar da vida cotidiana, dois elementos indissociáveis como as duas faces de uma moeda. Aprender é participar, participar é aprender (BROUGÈRE, 2012a, p. 314).

As crianças aprendem no cotidiano, nas rotinas, colaborando nas tarefas dos adultos, e entre si, e vão solucionando problemas a seu modo. Através de interações com adultos e, também, entre pares. Os espaços onde atuam com mais liberdade potencializam suas experiências.

Sobre a necessidade de fazer coisas com mais liberdade, a seu modo, cita-se Korczak (1981), que proclamou "a libertação da criança, sem a qual a humanidade não teria qualquer sentido" (1981, p. 155). O filósofo Renaut (2002), por sua vez, com o propósito de contribuir para a liberação das crianças, lembra que elas possuem identidades próprias. O autor reconhece a função da Pedagogia, mas afirma que a “intervenção do mestre não deve comprometer a liberdade do aluno” (RENAUT,2002, p. 297). Renaut defende a liberação das crianças, o que poderá ser promovido através de um exercício de autoridade praticado horizontalmente, no qual prevaleçam negociações e diálogos entre adultos e crianças.

Carvalho, Pedrosa e Rossetti-Ferreira (2012), em seu livro Aprendendo com a criança de zero a seis anos, procuram explicar como as crianças ensinam os adultos. As autoras valorizam, nas ações das crianças, a afetividade, a motricidade, o raciocínio e a linguagem, elementos presentes na Rede de Significações, metáfora utilizada pelas autoras que tem por função representar os processos de desenvolvimento “a 
partir de configurações que articulam vários elementos em contínua interação e transformação" (CARVALHO, PEDROSA, ROSSETTI-FERREIRA2012, p. 81-82). Para elas,

\begin{abstract}
as relações entre os seres vivos e seus meios são complexas e dialéticas, envolvendo muitos níveis e campos interacionais, estes possuem suas particularidades: motivos, emoções, capacidade motora, cognitiva, fase de vida etc. O meio é também circunscrito, ele possibilita ou não certas modalidades interacionais e é também construído nas interações (CARVALHO; PEDROSA; ROSSETTI-FERREIRA, 2012, p. 81-82).
\end{abstract}

No que diz respeito à imaginação, ela surge das experiências. Portanto, Vigotski (1996) adverte que é um equívoco achar que as crianças têm mais imaginação do que os adultos.

Para Vygotsky (1996), a imaginação não surge do nada, mas sim de elementos da experiência anterior. Não há separação entre realidade e a fantasia. Quanto mais rica for a experiência, maior será o material de que se dispõe a imaginação. Daí a importância de oportunizar que as crianças brinquem, quer seja interagindo com os adultos, quer com crianças e objetos (MULLER; CARVALHO, 2009, p. 76).

Considerando que as crianças vêm de diferentes contextos culturais, é necessário ficar atento àquilo que elas trazem do seu meio, inclusive se oriundas do meio rural ou urbano, conforme descrito numa das cenas supramencionadas. A perspectiva intercultural oferece importantes contribuições à educação com relação ao ser e estar no mundo, que apresenta suas particularidades.

A educação intercultural acontece quando é possível criar contextos educativos capazes de oportunizar a integração e interação tanto criativa quanto cooperativa, crítica e efetiva entre diferentes sujeitos e diferentes contextos sociais e culturais; esta relação se constitui baseada na troca e na reciprocidade entre pessoas, transpondo a dimensão individual dos sujeitos e envolvendo pertencimentos e identidade (COPPETE; FLEURI; STOLTZ, 2012, p. 341).

Nas brincadeiras relacionadas aos faz de conta, as crianças criam um mundo de fantasias: princesas, reis e fadas encontram-se no dia a dia, os super-heróis salvam mocinhas, e, também, transformam-se em pais e mães, professoras e médicos. Segundo Kishimoto (2008), esse tipo de brincadeira "surge com o aparecimento da representação e da linguagem, em torno dos $2 / 3$ anos, quando a criança começa a alterar o significado dos objetos" (KISHIMOTO, 2008, p. 39).

Observando os exemplos de aprendizagem e manifestação da construção cultural das crianças na rotina do dia a dia, reafirma-se que diversas formas de aprendizagens ocorrem no cotidiano. Conforme Brougère (2012b), o cotidiano "não é apenas o espaço da rotina, mas também aquele onde se estruturam aprendizagens informais" (BROUGÈRE, 2012b, p. 20).

De acordo com Vigotski (1998), a criança inventa os brinquedos quando começa a experimentar tendências irrealizáveis: os desejos não satisfeitos criam tensões. Então, ela usa a imaginação para solucionar as tensões. A situação imaginária representa uma forma humana de atividade.

Por todo o tempo, no decorrer dos três meses em que as crianças foram observadas, ocorriam trocas de saberes/aprendizagens. Dessa forma, durante as conversas, o ouvir o outro da mesma idade possibilita novas aprendizagens, novos conceitos vão sendo constituídos, enriquecido o universo, elaboradas as culturas infantis. No cotidiano, e de forma espontânea, vão surgindo vários temas de interesse das crianças. Seguem cenas vinculadas ao gênero e à diferença de sexo:

Cena 9: Crianças brincando com massinha de modelar. Eu me aproximo. 
Jonas faz unhas com a massinha de modelar. Ao lado, Camila diz:

- 'Você não pode fazer as unhas de massinha'.

- Jonas: 'Por quê? Meninos não têm unhas?’ (Diário de Campo, 30-09-2015).

A esse respeito, cita-se Korczak, que pontua:

Se os adultos não estivessem sempre a nos lembrar que este é um garoto e esta é uma menina, é provável que a gente nem lembraria. Mas que esperança: eles não nos deixam esquecer. Dizem da boca para fora que não há diferença, mas na prática fazem exatamente o contrário (KORCZAK, 1981, p. 131-132).

Um dos espaços propícios para a brincadeira livre, o parque, trouxe uma experiência um tanto surpreendente. Apresenta-se, a seguir, um desabafo registrado no Diário de Campo:

\begin{abstract}
Estou apavorada. Quando iniciei os estudos, esperava que o espaço do parque pudesse me render grandes 'histórias'. Bom, até aconteceram algumas, mas nem perto do que esperava. Quando as crianças saem da sala, em filas, cantarolando a música do trem, aparentemente a brincadeira do parque seguirá a mesma tranquilidade. Mas, não é assim que acontece. É o terceiro dia de observação no parque e a cena se repete. Quando as crianças chegam ao espaço é como se estivessem recebendo uma carta de alforria. As correrias e os gritos são tantos que é difícil acompanhar quaisquer brincadeiras. Com o passar do tempo, felizmente, os ânimos foram se acalmando para a tranquilidade tanto da professora, que precisa cuidar das 24 crianças, quanto para a minha, que necessito descobrir quais aprendizagens permeiam aquela ocasião (Diário de Campo, 16/09/2015).
\end{abstract}

O parque é outro espaço de brincadeiras, que vai além das paredes da sala de aula. A euforia expressa em gritos e corre-corre pode ter diferentes explicações. A liberdade com certeza é uma delas, seguida da proximidade com a natureza, o contato com crianças de outras idades, com os brinquedos, com a areia e, principalmente, com o espaço mais amplo e livre. A alegria nos olhos dos pequenos é demonstrada através das brincadeiras.

Friedmann (2012) considera as brincadeiras como linguagens infantis e afirma que:

As brincadeiras constituem, assim mesmo, linguagens infantis, considerando a linguagem qualquer meio sistemático de comunicar ideias ou sentimentos por meio de signos. Um dos grandes desafios que as linguagens lúdicas nos propõem é a leitura e tradução dessas 'falas' infantis (FRIEDMANN, 2012, p. 25).

A euforia abre espaço para a brincadeira. Uma questão interessante de esclarecer numa das ocasiões em que se foi ao parque é: será que as crianças reconhecem sua agitação? O registro que segue pode melhor explicar: “Cena 10: Enquanto se aguarda para ir ao parque, Nicolas olha para a pesquisadora e diz: ‘Sabeo que a gente faz no parque? A gente grita'. 'É, eu sei’! (Diário de Campo, 02/10/2015).

As crianças explicitam, também no parque, o que elas aprendem com relação aos papéis sociais, masculino-feminino. Como as outras regras do saber-viver, as que dizem respeito às relações entre meninas e meninos aparecem em cenas como esta a seguir:

Cena 11: As crianças brincam na areia do parque e uma das pesquisadoras se aproxima delas. Duas crianças brincam com areia com baldinhos. Após um tempo de observação, Vitória diz:

- ‘Oh, Mateus dá para mim um pouquinho' (pedindo um pouco de areia).

Mateus: - 'Eu posso cavar bem rápido se você quiser.'

Vitória: - 'Então eu vou te ajudar.'

Mateus: - 'Não, eu cavo e tu faz [sic] a comida. Mas você é a menina.'

Vitória: - 'E você é o menino.' (Diário de Campo, 05/10/2015). 
Uma das crianças, com interesse de continuar brincando e fazendo o que queria, tenta convencer a amiguinha de que pode "cavar bem rápido", demonstrando sua competência. Ressalta a divisão de trabalho entre menino e menina, e a limitação das fronteiras entre eles. A brincadeira com areia é uma das que mais possibilitam a revelação da apropriação do patrimônio lúdico, segundo Delalande (2003), uma vez que a areia é um material aberto à imaginação. O menino inventa para a menina uma brincadeira de "menina": "Você faz a comida". Como afirma Korczak (1981):

Se estamos cansados ou sem muita vontade de brincar, ou se alguém faz alguma coisa que não é mesmo permitida, o jogo é interrompido e começa a discussão. Não se trata bem de discutir, seria mais para descansar um pouco, ou modificar alguma coisa na brincadeira, introduzir um aperfeiçoamento. Põe-se alguém para fora, admita-se um outro; ou então o cão vira lebre, ou coisa parecida. Ou alguém inventa outra brincadeira (KORCZAK, 1981, p. 49).

Também foi observada a curiosidade infantil no que diz respeito à diferença entre os sexos. É sobre esta questão que se apresenta a seguinte cena:

Cena 12: Na sala Bruna está de minissaia, durante a brincadeira, ela se senta e abre suas pernas, mostrando, assim, sua calcinha. Quando percebe que os colegas estão rindo e 'se divertindo', ela repete o movimento corporal por umas cinco vezes.

As crianças vão chamando mais colegas e expressando frases como: 'Olha a calcinha dela', 'Olha a perereca [sic] dela', 'Olha a bunda [sic]' [...].

Logo que ela para, começa a brincar de outras coisas, vai para outros espaços da sala, mas Alexandre passa a segui-la e levantar sua saia. Ela acha graça e continua fugindo, fazendo daquele momento uma brincadeira.

Quando a estagiária questiona o que os meninos estão fazendo, já que percebe que eu os observo, Alexandre diz que estão só brincando. Disfarçadamente, continuo observando. Até que de tanto Alexandre persegui-la, eles (Alexandre e Bruna) se encontram, se abraçam e depois ele levanta sua blusa e beija sua barriga.

Eu tento me aproximar para ouvir as falas, porém, não pretendia acabar com a brincadeira. Quando chego mais perto, eles saem correndo. E continuam correndo e o menino levantando sua saia por alguns minutos.

Quando eu noto que a brincadeira acabou, aproximo-me e pergunto por que ele estava levantando a saia da amiga (tentei usar um tom mais amigável possível, para que não parecesse uma repreensão). Ele fica aparentemente com vergonha e nada diz.

Para convencê-lo a falar digo: 'Conta pra [sic] tia, será nosso segredo'. Ele diz: 'A bunda [sic] dela’. E sai correndo (Diário de Campo, 30-09-2015).

A cumplicidade entre as duas crianças na cena recém-descrita evidencia as relações entre meninos e meninas longe dos adultos. Delalande (2003) afirma a esse respeito:

A aprendizagem da diferença dos sexos começa para todo indivíduo desde o nascimento, observando o papel que virá a ser assumido por cada um deles. Na escola, os alunos têm o prazer de experimentar o que provoca neles a confrontação a outro sexo (desejo ou rejeição, imagem de si) e aprendem a gerenciar isso socialmente, através do jogo (DELALANDE, 2003, p. 11).

Uma última observação a ser mencionada neste artigo, diz respeito ao que as crianças desenharam no Diário de Campo. Nele elas expressaram, através de desenhos, garatujas, e fragmentos, alguns dos seus conceitos, algumas aprendizagens e, em particular, exprimiram seu afeto para com a pesquisadora, ofertando-lhe: desenhando flores, castelo da princesa, cobras pontilhadas, bolinhas, etc.

Uma criança disse: "Vou desenhar flores para a tia".

E assim o caderninho amarelo passa a ser disputado por elas. Em várias ocasiões foi possibilitado o acesso a esse material, mas esse dia foi diferente: elas disputaram o caderninho da tia: disputaram-no mais fortemente, mas também permitiram que o amigo desenhasse, perguntaram o que queria que fizessem, e foi assumida uma posição 
que pudesse dar-lhes asas à liberdade de criação. Elas demonstram adorar. No decorrer dos vários dias de encontro, vários traços e riscos, e bolinhas decoraram e foram ilustrando o diário. Surgiram fragmentos de desenhos os quais foram guardados com todo carinho. Mas, nesse dia foi diferente: algumas crianças resolveram oferecer como presentes, os desenhos. (Diário de Campo, 02/10/2015).

A linguagem simbólica, usada pelas crianças no Diário de Campo, de acordo com Ferreira (2007), têm a potência de possibilitar aos humanos compreender o mundo e também criar, produzir e transformar este mesmo mundo, aos outros e a si próprio. Através delas são construídos sentimentos, idéias e expressões, sensações e pensamentos. As linguagens permitem compartilhar conceitos e memórias com os demais - construir uma vida e trajetória coletiva (FERREIRA, 2007, p. 47).

Nos desenhos, é possível perceber a criatividade, a imaginação e a construção de conceitos e símbolos; identificar temas de interesse das crianças expressos através da linguagem gráfica. Tendo sido feitas essas últimas considerações sobre as produções infantis, chama-se, finalmente, a atenção para uma reflexão de Friedmann (2012) sobre o brincar adulto:

Enfim, devemos reaprender a brincar! Com o nosso corpo, o nosso espaço e nossos objetos; com a imaginação, a criatividade, a inteligência; com nossa intuição, as palavras e os nossos conhecimentos; com nós mesmos e com os outros. Assim, estaremos redescobrindo essa linguagem, a linguagem do lúdico, para nos comunicarmos e nos expressarmos (FRIEDMANN, 2012, p. 162).

Compreender a infância como um período de descobertas, de construções, de adaptações é fundamental para estabelecer relações com as crianças. As aprendizagens são possibilitadas pelas brincadeiras, que oportunizam o "estar junto" e a construção da cultura infantil. A respeito disso, Brougère aponta que “a aprendizagem não é aí, necessariamente intencional [...], é informal, implícita, incidente, da ordem da socialização ou aculturação" (2012b, p. 15).

As rotinas das tardes, nas duas turminhas observadas, não eram muito diferentes. Geralmente, a chegada da pesquisadora acontecia enquanto as crianças ainda dormiam. Depois, acordavam, calçavam os sapatos, lavavam os rostos e aguardavam o momento do café, às vezes, com músicas e TV. Na sequência, brincavam e, em alguns dias, iam ao parque. Nesses momentos, tão corriqueiros, acabavam acontecendo episódios magníficos, nos quais as crianças podiam assumir a condição de atores de situações, inclusive como protagonistas, e coconstrutoras da cultura/sociedade (CORSARO, 2011).

\section{Considerações finais}

Este artigo teve como propósito socializar dados da investigação de viés etnográfico, realizada com 24 crianças de 3-4 anos de um CEI de uma cidade do sul de Santa Catarina. Não foi possível esgotar todo o conteúdo da pesquisa num só artigo, tendo sido apresentados registros de observações de dois dos três meses em que elas foram investigadas e apenas algumas das categorias que compuseram a análise dos resultados, tais como, por exemplo, interações: eu e o outro; contextos culturais; construção de grupos: inserção/exclusão; brincadeiras e jogos de papéis sociais; questões de gênero e curiosidade sexual; interações pesquisadoras-criança. O contexto da pesquisa foi apresentado, salientando o papel desempenhado pela pesquisadora junto às crianças. Corsaro (2011) e Rinaldi(1999), entre outros autores mencionam quanto é importante, para o sucesso da pesquisa. 
Embora a quantidade de observações e o tempo de permanência com as crianças não tenham sido exaustivos - foram só três meses de convívio com elas, dos quais só registros dos dois primeiros meses foram apresentados neste artigo, considera-se que a experiência foi muito significativa, o que o demonstram as descrições de algumas cenas e, também, as possibilidades de reflexões por elas suscitadas. Perceberam-se a riqueza e a complexidade das interações entre pares, desenvolvidas no cotidiano, que culminaram com algumas trocas de conhecimentos/aprendizagens na sociedade infantil. Esta, como se observou, não é totalmente autônoma. Logo, existe uma interdependência entre as sociedades dos adultos e da infância.

As crianças constituem um grupo social, a(s) infância(s), que deve ser considerado por inteiro, completo, no momento presente, numa perspectiva, inclusive, cultural. Como os contextos culturais são diversos, parece ser conveniente usar o termo infância no plural.

Ao se falar de uma cultura de pares, atribui-se às crianças uma capacidade de, a partir da cultura dos adultos a qual elas, também, pertencem, interpretarem, transformarem, inovarem aquela, e também construírem a sua cultura. Quando, por exemplo, Renaut (2002) insiste na liberação das crianças e Delalande (2003, 2012), assim como Corsaro (2011), entre outros, mencionam a importância de que sejam realizadas observações das crianças em situações e espaços onde elas estejam mais livres, onde elas experimentam uma autonomia relativa, não significa que eles estejam dissociando sua cultura daquela dos adultos.

As observações realizadas sobre as crianças, apresentadas neste texto, demonstraram a presença hierarquizada nas relações entre as crianças pequenas, a existência de líderes e crianças a eles submissas, em diversas situações, inclusive, por ocasião das brincadeiras com areia. As lideranças estariam relacionadas a certo grau de competência, até mesmo de rapidez na execução de tarefas atribuídas por eles como sendo específicas de meninos. Nos embates ocorridos um dos argumentos "fortes" culminaram com o "você é a menina", mas "você é o menino", marcando fronteiras. Elas fazem uma distinção de papéis sociais, embora não seja claro se existe uma "superioridade" dos meninos sobre as meninas ou vice-versa.

A defesa do espaço da brincadeira, ou mesmo da tarefa exigida por ela, pautou-se muito na "clareza" dos papéis sociais assimilados e interpretados por elas, reforçando a construção da identidade individual e social.

A "submissão" às regras dos grupos, por sua vez, ocorreu em função da necessidade/desejo de ser aceito: é preciso comportar-se de acordo com as regras para não ficar isolado. Assim, pequenos grupos giraram em torno do saber-fazer de algumas dentre elas. No entanto, o coração, também, fala alto: surgiram demonstrações de empatias. Elas, também, funcionaram como "ponto de corte" com relação àqueles que podem e devem ser incluídos nas brincadeiras. Foram detectados sentimentos de proteção, de solidariedade para com o colega. Tais sentimentos criam uma ligação entre as crianças e as estimulam a agirem com mais independência do adulto, inclusive, para se "protegerem" de sua autoridade, embora permaneçam sendo alvos de seu controle.

Sabe-se que as relações afetivas, particularmente entre crianças pequenas, não são duradouras, permanecem, às vezes, até a mudança de interesse por determinada brincadeira ou brinquedo. Elas são 
constituintes dos sujeitos. Nas cenas mencionadas, não houve agressões físicas durante o período das observações: nas poucas ocasiões em que as crianças "estranharam-se" foram os próprios colegas que ajudaram a desfazer os mal-entendidos.

Constatou-se a importância de deixar as crianças em situações onde elas possam ficar mais livres para criarem suas brincadeiras e construírem suas redes de comunicação utilizando várias linguagens: oral ou não. A alegria expressa pelos olhos dos pequenos e a satisfação de poder "fazer", agir sozinhas, foram evidenciadas nas brincadeiras que, segundo Friedmann (2012,p.25), "constituem, assim mesmo, linguagens infantis, considerando a linguagem qualquer meio sistemático de comunicar ideias ou sentimentos por meio de signos. Um dos grandes desafios que as linguagens lúdicas nos propõem é a leitura e tradução dessas 'falas' infantis".

Nas observações realizadas foi constatada a tendência, por parte das crianças, em interagir, comunicar-se, jogar e, inclusive, proteger-se entre pares. Foram percebidas diversas modalidades interativas entre elas, constituindo suas próprias redes sociais e suas culturas.

A relação com as crianças, na maior parte das vezes, deu-se de forma tranquila e agradável, tanto para elas quanto para a pesquisadora. Desta exige-se sensibilidade para saber dialogar e frequentar o espaço das crianças sem, contudo, tornar-se uma invasora. Nessa perspectiva, Gandini e Goldhaber (2002) ressaltam que:

Através da observação e da escuta atenta e cuidadosa às crianças, podemos encontrar uma forma de realmente enxergá-las e conhecê-las. Ao fazê-lo, tornamo-nos capazes de respeitá-las pelo que elas são e pelo que elas querem dizer. [...] para um observador atento, as crianças dizem muito, antes mesmo de desenvolverem a fala (GANDINI; GOLDHABER, 2002, p. 152).

No que diz respeito à ação educativa dos adultos, alerta-se para o fato de que não deve ser excluído nem supervalorizado nenhum tipo de educação. Ao contrário: propõe-se a adoção de um conceito de educação mais amplo, que enfatize uma articulação entre educação familiar, escolar e a denominada educação informal. Entende-se que na formação dos professores é importante sensibilizá-los, inclusive, para realizarem, em suas classes, observações de viés intercultural, para captar os saberes informais, que constituem o que se costuma denominar de "currículo oculto".

A diversidade cultural não será percebida como um problema a mais para o professor se a pedagogia for intercultural e não etnocentrada. A superação de tal visão conduz à "compreensão e respeito pela diversidade cultural e pelo viver junto", segundo Dasen (apud NGENG, 2012, p. 304). O autor sugere que sejam considerados, na formação dos professores, o modelo do Nicho do Desenvolvimento, que coloca as crianças no centro dos interesses, valoriza as especificidades do meio em que elas vivem, bem como uma adaptação do meio às necessidades das crianças. Não devem ser descartadas as preocupações com o ambiente psíquico e social das crianças, a oferta de um conjunto de atividades que favoreçam a socialização/aculturação, que são de responsabilidade dos educadores, nem as opiniões dos pais sobre o que eles consideram ser desenvolvimento e educação das crianças.

Porém de nada adiantará apresentarem-se "modelos teóricos" se as crianças forem alijadas de um processo que lhes diz respeito. Elas precisam ser compreendidas, ouvidas e observadas. Elas integram 
diretamente o processo, podendo assumir, muitas vezes, o protagonismo das ações, inclusive quanto ao seu pertencimento a um grupo de pares, e aos grupos sociais mais amplos, no quais podem obter proteção, reconhecimento e consolidar suas identidades individuais e sociais.

\section{Referências}

BORBA, Ângela Maria. O brincar como um modo de ser e estar no mundo. In: BRASIL. MEC/SEB. Ensino fundamental de nove anos: orientações para a inclusão da criança de seis anos de idade. Organização de JeaneteBeauchamp, Sandra Denise Rangel, Aricélia Ribeiro do Nascimento. Brasília: Ministério da Educação, Secretaria de Educação Básica, 2007.

BROUGÈRE, Gilles. Uma teoria de aprendizagem adaptada: a aprendizagem como participação. In: BROUGÈRE, Gilles; ULMANN, Anne-Lise (Org.).Aprender pela vida cotidiana.Campinas: Autores Associados, 2012a. pp. 307-320.

Vida cotidiana e aprendizagem. In: BROUGÈRE, Gilles; ULMANN, Anne-Lise. (Org.). Aprender pela vida cotidiana. Campinas: Autores associados, 2012b. pp. 11-24.

BROUGÈRE, Gilles; ULMANN, Anne-Lise. Introdução: Sair da sombra: as aprendizagens cotidianas. In: . (Orgs.). Aprender pela vida cotidiana. Campinas: Autores Associados, 2012. pp. 1-7.

CARVAlHO, Ana; PEDrosA, Maria Isabel; ROSSETTI-FERREIRA, Maria Clotilde. Aprendendo com as crianças de 0 a 6 anos. São Paulo: Cortez, 2012.

COPETE, Maria Conceição; FLEURY, Reinaldo Matias; STOLTZ, Tania. Educação para a diversidade numa perspective intercultural. Revista Pedagógica Unochapecó, jan./jun. 2012, ano 15, n. 28, v. 01, $341-345$.

CORSARO, William A. Sociologia da Infância. Porto Alegre: Artmed, 2011.

DELALANDE, Julie. O pátio de recreio: lugar de socialização e de cultura infantis. In: BROUGÈRE, Gilles; ULMANN, Anne-Lise (Orgs.). Aprender pela vida cotidiana. Campinas, SP: Autores Associados, 2012. pp. 65-80.

. Cultureenfantine et règles de vie. Terrain,mars 2003, 40, 1-16.

FERREIRA, Valéria Silva. Infância e linguagem escrita: práticas docentes. Itajaí: UNIVALI, 2007. 
FLORESTAN FERNANDES. As Trocinhas do Bom Retiro; contribuições ao estudo folclórico e sociológico da cultura e dos grupos infantis. Pró-Posições, jan./abr. 2004, v. 15, n. 1(43), 229-251.

FRIEDMANN, Adriana. O brincar na educação Infantil: Observação, adequação e inclusão. 1. ed. São Paulo: Moderna, 2012.

GANDINI, Lella; GOLDHABER, Jeanne. "Duas reflexões sobre a documentação”. In: GANDINI, Lella; EDWARDS, Carolyn. Bambini: A abordagem italiana à educação infantil. Porto Alegre: Artmed, 2002. pp. 150-169.

KISHIMOTO, TizukoMorchida. Jogo, brinquedo, brincadeira e a educação. 11. ed. São Paulo: Cortez, 2008.

KORCZAK, Janusz. Quando eu voltar a ser criança. Tradução de Fanny Abramovich. São Paulo: Summus, 1981.

MONTANDON, Cléopâtre; LONGCHAMP, Philippe. Você disse autonomia? Uma breve percepção da experiência das crianças. Perspectiva, Florianópolis, jan./jun. 2007, v. 25, n. 1, 105-126, NUP/UFSC.

MULlER, Fernanda; CARVALHO, Ana Maria Almeida. Teoria e prática na pesquisa com crianças: Diálogos com Willian Corsaro. São Paulo: Cortez, 2009.

NGENG, Lysette. Nicho do desenvolvimento e abordagem intercultural. In: BROUGÈRE, Gilles; ULMANN, Anne-Lise (Orgs.). Aprender pela vida cotidiana. Campinas, SP: Autores Associados, 2012. pp. 293-306.

RENAUT, Alain. La liberationdes enfants: contibutionphilosophique à uma histoire de l'enfance. Bruxelles: Bayard Calmann-Lévy, 2002.

RINALDI, Carlina. “O currículo emergente e o construtivismo social”. In: EDWARDS, Carolyn et al. As cem linguagens da criança: A abordagem da ReggioEmilia na educação da primeira infância. Porto Alegre: Artmed, 1999. pp. 113-122.

SIROTA, Régine. A socialização no cotidiano: os trunfos de uma etnografia do minúsculo. In: BROUGÈRE, Gilles; ULMANN, Anne-Lise (Orgs.). Aprender pela vida cotidiana. Campinas, SP: Autores Associados, 2012, pp. 279-288. 
Élémentspour une sociologie de l'enfance. Rennes: PUF, 2006. pp. 37-41.

VIGOTSKI, Lev Semenovitch. Pensamento e Linguagem. São Paulo: Martins Fontes, 1998.

WALLON, Henri. As origens do pensamento da criança. Tradução de Doris Sanches Pinheiro, Fernanda Alves Braga. São Paulo: Manole, 1989. 